\title{
PEMETAAN DAN PEMERATAAN GURU BERDASARKAN BEBAN MENGAJAR GURU SMP NEGERI DI KECAMATAN TENAYAN RAYA PEKANBARU
}

\author{
Endang Kilatsih ${ }^{1}$ \\ Zulfan Saam ${ }^{2}$ \\ Sumarno $^{2}$ \\ ${ }^{1}$ Post Graduate Student of Riau University
${ }^{2}$ Lecturer of Education Management Study Programme PPs University of Riau
}

\begin{abstract}
This study aims to determine the teachers state map, equity-based teacher teacher's teaching load Junior High School in District Tenayan Raya Pekanbaru. Informants to be interviewed in this study were school principals, teachers, school supervisors and Head of the Education and Culture junior Pekanbaru. Instruments used in the form of interview, observation and documentation. Analysis of the data used to describe the data mapping and equal distribution of teachers by teachers' teaching load Junior High School in District Tenayan Kingdom is a qualitative analysis. The results showed that the first, the implementation of the mapping program and the equal distribution of teachers has not gone well in school because teachers are still many shortcomings. Secondly, There are many teachers who have not been able to meet the mandatory teaching load at least 24 hours per week face to face. Third, the solution of barriers to the implementation of the program of mapping and generalization of junior high school teachers throughout the District Tenayan Raya Pekanbaru consists of several things of which to be transparent and accountable, carried out by the condition and where teachers live and give them the benefit of the mutation teacher to all the assembly of teachers in the environment of the District Tenayan Raya Pekanbaru.
\end{abstract}

Key words: mapping, equal distribution of teachers, teaching loads

\begin{abstract}
Abstrak: Penelitian ini bertujuan untuk mengetahui peta keadaan guru, pemerataan guru berdasarkan beban mengajar guru SMP Negeri di Kecamatan Tenayan Raya Pekanbaru. Informan untuk diwawancarai dalam penelitian ini adalah kepala sekolah, guru, pengawas sekolah dan kepala bidang SMP Dinas Pendidikan dan Kebudayaan Pekanbaru. Instrumen yang digunakan berbentuk wawancara, observasi dan dokumentasi. Analisis data yang digunakan untuk memaparkan data pemetaan dan pemerataan guru berdasarkan beban mengajar guru SMP Negeri di Kecamatan Tenayan Raya adalah analisis kualitatif. Hasil penelitian menunjukkan bahwa pertama, pelaksanaan program pemetaan dan pemerataan guru belum berjalan dengan baik sebab disekolah masih banyak kekurangan guru. Kedua, Masih banyak guru yang belum dapat memenuhi beban mengajar wajib minimal 24 jam tatap muka per minggu. Ketiga, solusi dari hambatan pelaksanaan program pemetaan dan pemerataan guru SMP se-Kecamatan Tenayan Raya Pekanbaru terdiri dari beberapa hal diantaranya dilaksanakan secara transparan dan akuntabel, dilaksanakan dengan melihat kondisi dan tempat guru tinggal dan memberi pemahaman mengenai manfaat dari mutasi guru kepada semua majelis guru yang ada di lingkungan Kecamatan Tenayan Raya Pekanbaru.
\end{abstract}

Kata Kunci: pemetaan, pemerataan guru, beban mengajar

\section{PENDAHULUAN}

Guru merupakan salah satu faktor penentu mutu pendidikan yang berada pada barisan depan dalam menciptakan sumber daya manusia dan berhadapan langsung dengan peserta didik melaluiproseskegiatanbelajarmengajar di kelas. Ditangan gurulah akan dihasilkan peserta didik yang berkualitas baik akademik maupun non akademik, mempunyai kematangan emosional, moral dan spritualyangtinggiuntukmenghadapi tantanganpadazamannyananti.

Untuk dapat menciptakan guru yang profesional dan berkomitmen dengan tanggung jawab 
yang diembannya maka berbagai program telah dilakukan guna meningkatkan kesejahteraan guru dan peningkatan kemampuan dan profesional dalam bekerja, seperti diadakannya sertifikasi guru dengan tujuan peningkatan mutu dan taraf hidup guru. Dengan diadakanya sertifikasi guru diharapkan guru dapat meningkatkan kemampuan dan lebih mempriorotaskan pekerjaan karena secara kebutuhan hidup juga sudah ditunjang dengan adanya sertifikasi yang dikeluarkan oleh pemerintah. Maka sangat diharapkan para guru yang notabene telah tersertifikasi dapat bekerja lebih profesional, bertanggung jawab dan berkomitmen dalam peningkatan kualitas pendidikan.

Namun beberapa kendala yang ditemui dilapangan, seperti penerapan beban kerja wajib mengajar 24 jam perminggu, peraturan yang berubah-ubah tentu dapat mempengaruhi kelancaran proses belajar mengajar disekolah, sehingga keadaan ini akan membuat guru kesulitan dalam memenuhi tuntutan beban kerja minimal yaitu 24 jam tatap muka perminggu. Bukan itu saja pembagian jam mengajar ini merupakan problem yang komplek bagi pemerintah dan sekolah, seperti tuntutan bagi guru yang bersertifikasi untuk dapat tatap muka 24 jam permimggu akan sulit dalam memenuhi tuntutan tersebut, sebab disekolah-sekolah tidak semua guru yang tersertifikasi namun harus tetap berbagi jam dengan guru yang telah tersertifikasi, dengan jam kerja yang sama namum dengan tunjangan yang berbeda. Kesulitan pemerataan tatap mukan 24 jam perminggu ini juga menjadi dilema tersendiri bagi guru sertifikasi tersebut denganjam mengajar yang tidak terpenuhi 24 jam tatap muka perminggu terkadang memuat tunjangan sertifikasi mereka tak bisa dikeluarkan.

Aturan 24 jam tatap muka perminggu ini menjadi problem tersendiri bagi guru dimana tuntutan yang harus dipenuhi bertolak belakang dengan kondisi nyata sekolah. Jumlah guru yang ada disuatu sekolah dengan jumlah jam mata pelajaran yang ada berimbang sehingga banyak guru yang tidak bisa mencapai jumlah jam wajib tersebut. Salah satu faktor sulitnya seseorang memenuhi jam tatap muka 24 jam itu adalah menumpuknya guru di sekolah-sekolah yang dianggap favorit di suatu daerah dan kurangnya jumlah rombel bagi guru yang mengajar di sekolah. Pemerataan guru yang belum sesuai dengan kebutuhan guru disetiap sekolah menyebabkan hal di atas menjadi persoalan yang tidak kunjungselesai. Dari bergulimya kurikulum satu ke kurikulum lain juga sebagai salah satu penyebab penjelasan pendidikan mengalami goncangan yang dapat menganggu guru dalam melaksanakan tugas.Aturan yang mengatur yang kian berganti tergantung situasi kondisi dapat menyebabkan terjadinya persepsi yang berbeda antara kalangan para ahli pendidik dalam mengambilsikap.

Untuk dapat menguraikan masalah ini perlu dilakukan pemetaan dan pemerataan guru baik dilihat dari profesionalisme kerja guru maupun dari jumlah guru yang tersertifikasi sebagai guru yang profesional dalam bidangnya. Pemetaan diperlukan untuk dapat mengkalkulasi jumlah guru yang ada disekolah, akan dapat dilihat sekolah mana yang memiliki kelebihan guru tertentu dan sekolah mana pula yang memiliki kelebihan guru tertentu. Dari hasil pemetaan ini maka akan mendapat acuan yang tepat bagaimana harus dilakukan pemerataan guru, dengan tujuan tentunnya semua guru akan mendapatkan jam mengajar yang sama yaitu 24 jam tatap muka permimggu.

Agar penataan dan pemerataan guru dapat direalisasikan dengan baik, maka perlu pemahaman yang sama antara berbagai pihak yang berkepentingan. Untuk itu, diperlukan sebuah petunjuk teknis yang dapat menjadi acuan bagi pemerintah provinsi atau Kabupaten/Kota, 
dinas pendidikan Kabupaten/Kota, dinas pendidikan Provinsi, dan unsur lain yang terkait dengan pelaksanaan penataan dan pemerataan guru pegawai negeri sipil. Petunjuk Teknis ini disusun sebagai acuan dalam implementasi peraturan bersama 5 Menteri dimaksud. Petunjuk teknis ini berisi hal-hal yang berkaitan denganperhitungankebutuhanguru, kriteria guru yang dipindahkan, wewenang instansi terkait terhadap pelaksanaan penataan dan pemerataan guru baik pemerintah maupun pemerintah daerah. Berdasarkan survey sementara yang peneliti lakukan terbukti bahwa ada beberapa masalah dalam distribusi guru diantaranya adalah: 1) kurang berfungsinya pengelolaan sumberdaya pendidik pada tingkat kota, 2) sekolah hanya melaporkan tentang kekurangan guru, jika ada kelebihan guru sekolah tidak melaporkan, 3) tidak ada kebijakan di terapkan bagi sekolah yang kelebihan guru, 4) 3 dari 6 SMP yang ada di Kecamatan Tenayan Raya majelis gurunya mengalamikesulitanpemenuhan jam kerja 24 jam tatap muka disebabkan oleh kelebihan guru, namun tiga SMP diantaranya mengalami kekurangan guru.

Berdasarkan beberapa aspek yang dapat ditinjau dalam penelitian ini, maka penelitian memfokuskan pada pengkajian pemetaan dan pemerataan guru Sekolah Menengah Pertama KecamatanTenayanRaya Pekanbaru.Subfokus:

1) Pelaksanaan pemetaan dan pemerataan guru Sekolah Menengah Pertama Kecamatan Tenayan RayaPekanbaru.

2) Faktor pendukung pelaksanaan pemetaan dan pemerataan guru Sekolah Menengah Pertama Kecamatan Tenayan Raya Pekanbaru.

3) Faktor penghambat pelaksanaan pemetaan dan pemerataan guru Sekolah Menengah Pertama Kecamatan Tenayan Raya Pekanbaru.

\section{METODOLOGI PENELITIAN}

Berdasarkan tujuan penelitian ini, maka penelitian ini menggunakan pendekatan deskriptif kualitatif. Pendekatan kualitatif dipandang lebih relevan untuk digunakan di dalam mengamati dan menganalisa fenomena-fenomena pada Pemetaan dan Pemerataan Guru Sekolah Menengah Pertama Negeri seKecamatan Tenayan Raya Pekanbaru. Pendekatan kualitatif dilaksanakan sebagaiupayamemahamisituasitertentudengan bentukpenelitianstudikasus.

Dalam penelitian ini data dan sumber data yang diambil adalah melalui Dinas Pendidikan dan Kebudayaan Kecamatan Tenayan Raya, dan Sekolah SMP Negeri di Kecamatan Tenayan Raya dan Kepala Sekolah SMP Negeri se- Kecamatan TenayanRaya.

Teknik pengumpulan data yang akan dilakukan adalah dengan melalui tahapan sebagai berikut : pengamatan, wawancara, membuat catatan lapangan, dan kajian dokumentasi.

\section{HASIL DAN PEMBAHASAN}

Berdasarkan gambaran umum SMP Negeri 9, 11, 26, 31 , 38 dan 49 Kecamatan Tenayan Raya Pekanbaru serta informasi yang peneliti peroleh dari informan/sumber data baik melalui wawancara, dokumentasi dan observasi lapangan serta dari rumusan masalah sebagaimana fokus penelitian yang peneliti tetapkan yaitu pemetaan dan pemerataan guru Sekolah Menengah Pertama Kecamatan Tenayan Raya Pekanbaru, maka temuan penelitian ini peneliti uraikan menurut subfokus penelitian sebagai berikut:

Subfokus 1 : Pelaksanaan pemetaan dan pemerataan guru Sekolah Menengah Pertama 


\section{Kecamatan Tenayan Raya Pekanbaru.}

Dari hasil wawancara yang peneliti lakukan baik dengan kepala bidang SMP dinas pendidikan, UPTD dan kepala sekolah memberikan penjelasan bahwa pada tahap pelaksanaan pemetaan dan pemerataan guru SMP di Kecamatan Tenayan Raya sudah dilakukan atas kerja sama semua pihak yang terlibat. Namun pelaksanaan pemerataan ini belum berjalan dengan baik terbukti dengan beberapa sekolah yang mengalami kekurangan guru dan dibeberapasekolah lain malah mengalami kelebihanguru.

Tabel 1 : Peta dan Keadaan Guru SMP di Kecamatan Tenayan Raya Tahun Pelajaran2016/2017

\begin{tabular}{|c|c|c|c|c|c|c|c|}
\hline No & $\begin{array}{c}\text { Nama } \\
\text { Sekolah }\end{array}$ & $\begin{array}{c}\text { Guru Mata } \\
\text { Pelajaran }\end{array}$ & $\begin{array}{l}\text { Jumlah } \\
\text { Rombel }\end{array}$ & $\begin{array}{c}\text { Jumlah } \\
\text { Jam }\end{array}$ & $\begin{array}{l}\text { Kebutuhan } \\
\text { Guru }\end{array}$ & $\begin{array}{c}\text { Guru } \\
\text { Yang } \\
\text { Ada }\end{array}$ & Kesimpulan \\
\hline 1 & 2 & 3 & 4 & 5 & 6 & 7 & 8 \\
\hline \multirow[t]{12}{*}{1} & SMPN 9 & P. Agama Islam & 27 & 3 & 3 & 3 & Guru cukup \\
\hline & Pekanbaru & $\mathrm{PKn}$ & & 3 & 3 & 3 & Guru cukup \\
\hline & & Bahasa Indonesia & & 6 & 7 & 11 & Guru lebih 4 \\
\hline & & Bahasa Inggris & & 4 & 4 & 7 & Guru lebih 3 \\
\hline & & Matematika & & 5 & 6 & 10 & Guru lebih 4 \\
\hline & & IPA Terpadu & & 5 & 6 & 8 & Guru lebih 2 \\
\hline & & IPS Terpadu & & 4 & 4 & 10 & Guru lebih 6 \\
\hline & & Seni Budaya & & 3 & 3 & 3 & Guru cukup \\
\hline & & Penjaskes & & 3 & 3 & 3 & Guru cukup \\
\hline & & Keterampilan/TIK & & 2 & 2 & 3 & Guru lebih 1 \\
\hline & & Muatan Lokal & & 2 & 2 & 1 & Guru kurang 1 \\
\hline & & Jumlah & & & 43 & 62 & \\
\hline \multirow[t]{12}{*}{2} & SMPN 11 & P. Agama Islam & 21 & 3 & 3 & 3 & Guru cukup \\
\hline & Pekanbaru & $\mathrm{PKn}$ & & 3 & 3 & 3 & Guru cukup \\
\hline & & Bahasa Indonesia & & 6 & 5 & 4 & Guru kurang 1 \\
\hline & & Bahasa Inggris & & 4 & 4 & 3 & Guru kurang 1 \\
\hline & & Matematika & & 5 & 4 & 5 & Guru lebih 1 \\
\hline & & IPA Terpadu & & 5 & 4 & 6 & Guru lebih 2 \\
\hline & & IPS Terpadu & & 4 & 4 & 4 & Guru cukup \\
\hline & & Seni Budaya & & 3 & 3 & 1 & Guru kurang 2 \\
\hline & & Penjaskes & & 3 & 3 & 2 & Guru kurang 1 \\
\hline & & Keterampilan/TIK & & 2 & 2 & 2 & Guru cukup \\
\hline & & Muatan Lokal & & 2 & 2 & 2 & Guru Cukup \\
\hline & & Jumlah & & & 37 & 35 & \\
\hline \multirow[t]{12}{*}{3} & SMPN 26 & P. Agama Islam & 19 & 3 & 2 & 5 & Guru lebih 3 \\
\hline & Pekanbaru & PKn & & 3 & 2 & 1 & Guru kurang 1 \\
\hline & & Bahasa Indonesia & & 6 & 5 & 5 & Guru cukup \\
\hline & & Bahasa Inggris & & 4 & 3 & 1 & Guru kurang 2 \\
\hline & & Matematika & & 5 & 4 & 5 & Guru kurang 1 \\
\hline & & IPA Terpadu & & 5 & 4 & 5 & Guru kurang 1 \\
\hline & & IPS Terpadu & & 4 & 3 & 7 & Guru lebih 4 \\
\hline & & Seni Budaya & & 3 & 2 & 1 & Guru kurang 1 \\
\hline & & Penjaskes & & 3 & 2 & 1 & Guru kurang 1 \\
\hline & & Keterampilan/TIK & & 2 & 2 & 1 & Guru kurang 1 \\
\hline & & Muatan Lokal & & 2 & 2 & 1 & Guru kurang 1 \\
\hline & & Jumlah & & & 31 & 33 & \\
\hline
\end{tabular}




\begin{tabular}{|c|c|c|c|c|c|c|c|}
\hline No & $\begin{array}{c}\text { Nama } \\
\text { Sekolah }\end{array}$ & $\begin{array}{c}\text { Guru Mata } \\
\text { Pelajaran }\end{array}$ & $\begin{array}{l}\text { Jumlah } \\
\text { Rombel }\end{array}$ & $\begin{array}{c}\text { Jumlah } \\
\text { Jam }\end{array}$ & $\begin{array}{l}\text { Kebutuhan } \\
\text { Guru }\end{array}$ & $\begin{array}{c}\text { Guru } \\
\text { Yang } \\
\text { Ada }\end{array}$ & Kesimpulan \\
\hline 1 & 2 & 3 & 4 & 5 & 6 & 7 & 8 \\
\hline \multirow[t]{12}{*}{4} & SMPN 31 & P. Agama Islam & 9 & 3 & 1 & 2 & Guru lebih 1 \\
\hline & Pekanbaru & $\mathrm{PKn}$ & & 3 & 1 & 1 & Guru cukup \\
\hline & & Bahasa Indonesia & & 6 & 2 & 2 & Guru cukup \\
\hline & & Bahasa Inggris & & 4 & 2 & 2 & Guru cukup \\
\hline & & Matematika & & 5 & 2 & 2 & Guru cukup \\
\hline & & IPA Terpadu & & 5 & 2 & 4 & Guru lebih 2 \\
\hline & & IPS Terpadu & & 4 & 2 & 3 & Guru lebih 1 \\
\hline & & Seni Budaya & & 3 & 1 & 1 & Guru cukup \\
\hline & & Penjaskes & & 3 & 1 & 0 & Guru kurang 1 \\
\hline & & Keterampilan/TIK & & 2 & 1 & 1 & Guru cukup \\
\hline & & Muatan Lokal & & 2 & 1 & 1 & Guru cukup \\
\hline & & Jumlah & & & 16 & 19 & \\
\hline \multirow[t]{12}{*}{5} & SMPN 38 & P. Agama Islam & 7 & 3 & 1 & 1 & Guru cukup \\
\hline & Pekanbaru & $\mathrm{PKn}$ & & 3 & 1 & 0 & Guru kurang 1 \\
\hline & & Bahasa Indonesia & & 6 & 2 & 2 & Guru cukup \\
\hline & & Bahasa Inggris & & 4 & 1 & 1 & Guru cukup \\
\hline & & Matematika & & 5 & 1 & 2 & Guru lebih 1 \\
\hline & & IPA Terpadu & & 5 & 1 & 2 & Guru lebih 1 \\
\hline & & IPS Terpadu & & 4 & 1 & 2 & Guru lebih 1 \\
\hline & & Seni Budaya & & 3 & 1 & 1 & Guru cukup \\
\hline & & Penjaskes & & 3 & 1 & 1 & Guru cukup \\
\hline & & Keterampilan/TIK & & 2 & 1 & 0 & Guru kurang 1 \\
\hline & & Muatan Lokal & & 2 & 1 & 1 & Guru cukup \\
\hline & & Jumlah & & & 12 & 13 & \\
\hline \multirow[t]{12}{*}{6} & SMPN 39 & P. Agama Islam & 8 & 3 & 1 & 1 & Guru cukup \\
\hline & Pekanbaru & PKn & & 3 & 1 & 1 & Guru cukup \\
\hline & & Bahasa Indonesia & & 6 & 2 & 0 & Guru lebih 2 \\
\hline & & Bahasa Inggris & & 4 & 1 & 3 & Guru lebih 2 \\
\hline & & Matematika & & 5 & 1 & 2 & Guru lebih 1 \\
\hline & & IPA Terpadu & & 5 & 1 & 1 & Guru cukup \\
\hline & & IPS Terpadu & & 4 & 1 & 2 & Guru lebih 1 \\
\hline & & Seni Budaya & & 3 & 1 & 1 & Guru cukup \\
\hline & & Penjaskes & & 3 & 1 & 1 & Guru cukup \\
\hline & & Keterampilan/TIK & & 2 & 1 & 1 & Guru cukup \\
\hline & & Muatan Lokal & & 2 & 1 & 0 & Guru kurang 1 \\
\hline & & Jumlah & & & 12 & 13 & \\
\hline
\end{tabular}

Subfokus 2: Faktor pendukung pelaksanaan pemetaan dan pemerataan guru Sekolah Menengah Pertama Kecamatan Tenayan Raya Pekanbaru

Temuan penelitian mengenai faktor pendukung pelaksanaan pemetaan dan pemerataan guru Sekolah Menengah Pertama Kecamatan Tenayan Raya Pekanbaru didapat dari wawancara yang dilakukan peneliti dengan Pengawas SMP, kepala sekolah dan majelis guru Darihasilwawancara tersebut diketahui mengapa perlu dilakukan pemetaan dan pemerataan guru di SMP Kecamatan Tenayan Raya Pekanbaru menyatakan bahwa, program ini penting dilakukan demi melihat keadaan guru disekolah- sekolah baik itu kekurangan maupun kelebihan untuk nantinya dilakukan pemerataan agar tidak ada yang dirugikan baik sekolah maupun murid. Landasan program ini tentunnya produk hukum dalam bentuk peraturan pemerintah (Gubernur/Walikota/Bupati) atau produk hukum lainya terkait penataan dan pemerataan guru PNS yang merujuk pada peraturan bersama. 
Serta program ini dilaksanakan atas desakan sekolah-sekolah mengenai kekurangan jumlah guru yang ada disekolah mereka, program ini dilaksanakan atas dasar pengembangan pendidikan dan mempermudah guru dalam beraktivitas sesuai dengan tuntutan mengajar mereka.

Jika program ini tidak dilaksanakan, sebagai contoh Dibeberapa SMP yang ada di Kecamatan Tenayan Raya saja banyak yang mengalami kekurangan guru dan belum menemukan solusi atas masalah ini dan yang paling tekena imbas atas tidak dilaksanakan program ini tentunya peserta didik yang harus menerima keadaan kekurangangurudisekolahmereka.

\section{Subfokus 3: Faktor penghambat pelaksanaan pemetaan dan pemerataan guru Sekolah Menengah Pertama Kecamatan Tenayan Raya Pekanbaru.}

Berdasarkan hasil wawancara peneliti dengan pihak-pihak yang terlibat, baik pengawas sekolah maupun kepala sekolah ada beberapa hambatan/kendala yang terjadi ketika program penataandanpemerataaninidilaksanakan, yaitu:

1. Kondisi guru (terutama guru honorer) disekolah yang sudah terlalu padat/banyak sehingga sulit untukmemetakanulang, baik di dalam Kecamatan maupun antar Kecamatan;

2 Ada permintaan khusus baik dari dalam (guru) maupun dari luar (keluarga yang lainya);

3. Guruyangsudahmempunyaitempattinggal yangmenetap;

4. Akreditasidansekolahyangmenjadifavorit.

\section{SIMPULAN DAN SARAN}

Berdasarkan temuan penelitian dan pembahasan tentang pemetaan dan pemerataan berdasarkan beban mengajar guru SMP Negeri di Kecamatan Tenayan Raya Pekanbaru, dapat disimpulkan:

1. Dari aspek pelaksanaan pemetaan dan pemerataan guru SMP Negeri di Kecamatan Tenayan Raya Pekanbaru. secara umum program ini sudah terlaksana semua pihak berperan sesuai dengan tupoksi dan wewenang masing-masing. Pengawas sekolah sebagai pelaksana dan petugas pengawas langsung telah melakukan tugasnya dengan sebaik mungkin dengan membangun komunikasi dengan Dinas pendidikan, Kepala Sekolah dan Guru. Tetap saja pelaksanaan ini masih terjadi kekurangan dibeberapa bagian, dan perlu ditingkatkan atau diperbaiki cara pelasanaannya agar tercapai tujuan dari pelaksanaan programini.

2. Dari aspek pendukung pemetaan dan pemerataan guru SMP Negeri di Kecamatan Tenaya Raya Pekanbaru pada tahap ini ada satu hal yang menurut peneliti sangat penting yang tidak peneliti dapatkan yaitu produk hukum dalam bentuk peraturan Walikota atau produk hukum lainnya terkait pemetaan dan pemerataan guru SMP Negeri di Kecamatan Tenaya Raya Pekanbaru yang merujuk pada peraturan bersama, yang merupakan faktor pendukung atau dasar dilaksanakanya program ini. Faktor lain yang mendukung pelaksanaan program ini ialah laporan dari rata-rata sekolah yang ada, tentang kekurangan tenaga pengajar disekolahmereka.

3. Dari aspek penghambat atau kendala yang dialami dalam pelaksanaan pemetaan dan pemerataan guru SMP Negeri di Kecamatan Tenayan Raya Pekanbaru terdapat beberapa 
hal yaitu: a). Guru tidak mau atau menolak untuk dimutasi ke sekolah dengan kualitas atau akreditasi yang lebih rendah dari tempat mengajar semula, b). Guru yang telah menetap disekitaran tempatmengajaryang lama,danc).Adanyapermintaan guruuntuk dimutasi kesekolahtertentu.

\section{DAFTAR PUSTAKA}

AG. Subarsono. 2009. Analisis Kebijakan Publik Konsep Teori dan Aplikasi. Yogyakarta: Pustaka Pelajar. Moleong. 2008. Metode Penelitian Kualitatif. Bandung. Rosda.

Muhammad Rialis. 2015. Pemetaan dan Pemerataan Guru berdasarkan beban kerja guru SMP di Kecamatan Kampar. Skripsi. Pekanbaru:UNRI.

Nogi Hasel. 2003. Good Corporate Finance Governance. Yogyakarta: Balaiurung dan Co.

Nugroho Riant. 2004. Kebijakan Publik Formulasi, Implementasi dan Evaluasi, Jakarta: T. Elek Media Komputindo.

Suhaimi Arikunto.2006. Prosedur Penelitian: Suatu Pendekatan Praktek. Jakarta: PT RINEKA Cipta.

Peraturan Bersama Menteri Pendidikan Nasional, Menteri Negara Pendayagunaan Aparatur Negara dan Reformasi Birokrasi, Menteri dalam Negeri, Menteri Keuangan, dan Menteri Agama. 2011. Tentang Penataan dan Pemerataan Guru Pegawai Negeri Sipil. Jakarta: Menteri Hukum dan Hak Asasi Manusia Republik Indonesia.Peraturan Menteri Pendidikan Nasional nomor 39 tahun 2009 tentang Pemenuhan Beban Kerja Guru dan Pengawas Satuan Pendidikan.

Peraturan Menteri Pendidikan Nasional Nomor 30 tahun 2011 tentang Perubahan atas Peraturan Menteri Pendidikan Nasional nomor 39 tahun 2009 tentang Pemenuhan Beban Kerja guru dan Pengawas Satuan Pendidikan. 